\title{
Social Transfers, Earnings and Low-Income Intensity Among Canadian Children, 1981-96: Highlighting Recent Developments in Low-Income Measurement
}

\author{
by John Myles* and Garnett Picot**
}

No. 144

11F0019MPE No. 144

ISSN: 1200-5223

ISBN: 0-660-18059-6

Price: $\$ 5.00$ per issue, $\$ 25.00$ annually

Business and Labour Market Analysis Division 24-F, R.H. Coats Building, Ottawa, K1A 0T6

*Florida State University and Statistics Canada

**Statistics Canada (613) 951-8214

Facsimile Number: (613) 951-5403

The paper is available on Internet: (www.statcan.ca)

March 2000

Authors are listed in alphabetical order.

The views presented in this paper are those of the authors only, and do not necessarily represent the views of Statistics Canada. 



\section{Table of Contents}

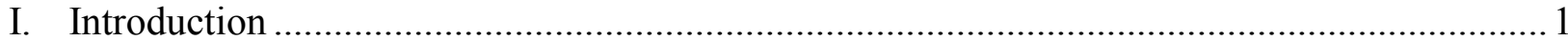

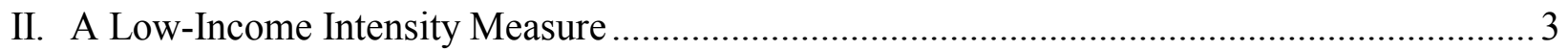

III. Low-Income Intensity Among Children, 1981-96 _........................................................... 7

Introduction and Methodological Considerations ............................................................. 7

Changes in Transfers, Market Incomes and Low-Income Intensity During the 1980s ............. 9

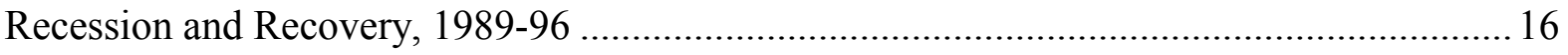

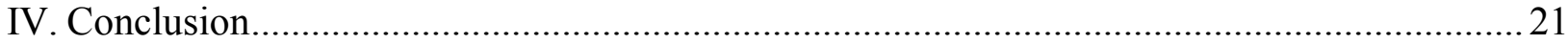

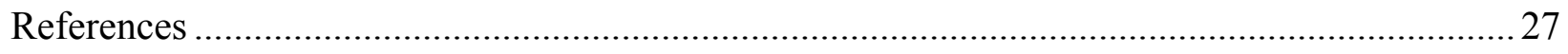





\section{Abstract}

A major aim of the paper is methodological. We contrast results using the SST (Sen-ShorrocksThon) index with results produced by the more familiar low-income rate, the usual measure for indexing low-income trends. The low-income rate is embedded in the SST index, but unlike the index, the rate incorporates only partial information on the distribution of low-income. Consequently, the low-income rate is generally unable to detect the changes we describe and this is true irrespective of the choice of low-income cut-off. Compared to the low-income intensity measure, the rate is also relatively insensitive to changes in transfer payments and employment earnings.

To demonstrate the methodological points, we revisit trends in low-income among Canadian children by taking advantage of recent developments in the measurement of low-income intensity. We focus in particular on the SST index and its elaboration by Osberg and Xu. Lowincome intensity among children declined in the 1980s but rose in the 1990s. Declining earnings put upward pressure on low-income levels over much of the period. Higher transfers more than offset this pressure in the 1980s and continued to absorb a substantial share of the increase through 1993. In contrast, between 1993 and 1996 employment earnings increased marginally, but government transfer declined more, no doubt due to both the slow recovery, when transfers typically decline, and program changes. The result was rising low-income intensity. The lowincome rate alone is an important, but only partial, guide to these developments. The lowincome intensity measure, by combining information on both changes in the rate and the gap (depth of low-income) provides a much more comprehensive view of trends, highlighting features often missed by trends in the rate alone.

Keywords: poverty, low-income, measurement 



\section{Introduction}

During the 1980s and early 1990s a number of articles appeared showing that in the face of declining employment earnings among low-income Canadians, and rising earnings inequality, the Canadian tax-transfer system had done a remarkably effective job in containing both income inequality and low-income rates in the Canadian population (Beach and Slotsve 1996; Blank and Hanratty, 1993; Picot and Myles, 1996, Wolfson and Murphy, 1998). The main message was that despite substantial change in the distribution of labour market incomes, change in the final distribution of income (after transfers and taxes) was glacial. Low-income rates and inequality did fluctuate with the ebb and flow of the business cycle, but taxes and transfers (as well as changing patterns of labour market participation and family formation) obviated the emergence of any secular trend. While no one claimed inequality or low-income rates were falling, the celebratory tone of these analyses was due in no small measure to the fact that the American taxtransfer system did not offset similar changes in the distribution of market incomes (Blank and Hanratty, 1993), resulting in rising income inequality and poverty in the United States.

Focus on low-income rates and earnings inequality continued in the 1990s. Low-income rates and income inequality did move up as the recession that began in 1990 set in and, as expected, declined again in 1994 as the economy began to grow. Unexpectedly, however, low-income rates turned up in 1995 and 1996 despite a weak recovery.

In this environment, the measurement of the low-income has once again come to the fore (Human Resources Development Canada, 1998). Identifying the impact of changing employment opportunities and government transfers on the economic well-being of populations has become a basic ingredient of modern political debate and contemporary policy analysis. And despite the long-standing debate over how to identify the "low-income" population, assessing the impact of changing economic circumstances and government transfers (and taxes) on those at the lower end of the income distribution occupies a prominent, and no doubt permanent, place in these discussions.

It is striking, then, that the standard approach to these questions (including Picot and Myles, 1996 and Picot, Myles and Pyper, 1998) relies on a class of low-income measures that are relatively insensitive to changes in employment earnings and social transfer payments, namely the lowincome rate. In his now classic article on the topic, Amartya Sen (1976) highlighted two problems for the measurement of low-income: (1) how to identify the low-income population (i.e. how to define a low-income cut-off or poverty line); and (2) how to construct a low-income index using all available information on the population identified by the cut-off, notably the "depth" of low-income. Most of the public debate, past and present, has been concerned with solving the first problem (Wolfson and Evans, 1989; HRDC, 1998), where and how to establish a low-income cut-off or poverty line, although Wolfson and Evans, along with others, have recommended the use of a low-income gap measure. As Sen demonstrated, however, the solution to the second problem is at least as important as the solution to the first and that, by itself, the familiar low-income rate does not satisfy the criteria for a useful low-income index. 
The objective of this paper is to review a low-income intensity measure that we believe is a more useful instrument for analyzing low-income trends and the effect of the tax/transfer system than is the low-income rate. To demonstrate the advantages of the intensity measure, we focus on lowincome among children.

Section one of the paper reviews recent developments in the measurement of low-income (or poverty) intensity that address these problems (Sen, 1976; Foster, Greer, and Thorbecke, 1984; Shorrocks, 1995; Osberg and Xu, 1997, 1998) We focus in particular on the Sen-ShorrocksThon (SST) index and its elaboration by Osberg and Xu $(1997,1998)$.

Measures of low-income intensity have not been widely used in policy circles in part because their abstract mathematical presentation have not provided policy-makers, scholars or the public with an intuitive understanding of their meaning. The recent work of Osberg and Xu (1997; 1998) largely overcomes this problem by presenting the Sen-Shorrocks-Thon index in a format that makes it easily accessible within traditional categories of low-income analysis. The lowincome intensity measure incorporates information on the low-income rate, the low-income gap and the distribution of the gap. ${ }^{1}$ Hence, the measure is sensitive not only to changes in the share of people in low-income (the rate), but also to changes in the average level and distribution of income among low-income families (the gap). Changes in the social transfer system, employment opportunities or anything else that affects either (1) the number of families in low-income or (2) the level and distribution of low-income will be captured by the intensity measure.

We then turn to a re-examination of low-income trends among Canadian children between 1981 and 1996, the most recent year for which data are available. Among other things we show that:

Low-income intensity among children declined somewhat through the 1980s, primarily a result of rising transfers. This change is largely invisible when measured by the low-income rate with the result that earlier studies have concluded that there was no change in low-income among children over the 1980 s.

Trends for the 1990s are the result of two distinct periods. Market earnings fell sharply between 1989 and 1993 (the recession years) and low-income intensity before transfers grew as a result. Per capita transfer payments continued rising over this period and offset a substantial share of the increase.

In contrast, during the period of recovery from 1993 to 1996, low-income intensity before transfers was relatively stable or even declined slightly, as employment earnings improved marginally. Social transfers, however, fell substantially, much more than employment earnings rose.

1 That is, the income gap between the cut-off and the low-income family's income. 
In general, trends in any low-income (or poverty) rate, the most commonly used indicator of lowincome trends, are an imperfect guide to these developments. This is in part because any improvement (or deterioration) in income among families below the cut-off are, by definition, ignored by the rate. It measures changes in the number of people in low-income, not how welloff they are. Comparison between low-income trends as indexed by the intensity measure and the rate show that:

Changes in the low-income rate usually correctly identify the direction of change in low-income intensity but not always. Between 1993 and 1996, low-income intensity among children rose but the low-income rate measured by the LICO fell slightly. More typically, small or negligible changes in the rate can mask much more substantial change in low-income intensity leading to the conclusion that there has been little or no change over periods when low-income intensity was in fact rising (or falling).

Qualitative conclusions about trends in low-income intensity are not very sensitive to the choice of a lower or higher low-income cut-off. Lower cut-offs tend to magnify the amount of change in some periods and deflate it in others as a function of where in the low-income distribution change is taking place.

Changes in the low-income rate are not a reliable indicator of the changing impact of the taxtransfer system on low-income intensity. For example, only about a third of the decline in lowincome intensity produced by increasing transfers in the 1980 s is captured by changes in the lowincome rate. Rising transfers had more impact on the low-income gap than the low-income rate. Conversely, changes in the low-income rate systematically underestimate the impact of falling transfers on low-income intensity between 1993 and 1996.

Before proceeding, a note on terminology is in order. While there is little consensus about its definition, the scholarly and technical literature on the topic typically uses the word "poverty" as a generic term for any income measure aimed at isolating the population at the lower end of the income distribution. Because of the definitional problems, Statistics Canada has always taken the position that its various low-income cut-offs should not be confused with "poverty" lines. We do not address this debate. We use the terms "poverty" and "low-income" interchangeably in our review of the scholarly and technical literature but follow the Statistics Canada convention exclusively in our empirical analyses which rely on the Statistics Canada cut-offs.

\section{A Low-Income Intensity Measure}

The target of Sen's (1976) critique was the widespread practice (then and now) of indexing trends with a simple headcount of the "poor", drawing a line to identify the population in the lower end of the income distribution and then measuring poverty with a poverty rate, the percentage of persons below the line. A reasonable test for any low-income index is to ask whether an increase or decrease in the index unequivocally indicates an increase or decrease of low-income in the population. As Sen (1976) pointed out, a low-income rate does not meet this standard. To motivate his discussion he used the example of a transfer of income from the very poor (making them worse off) to the not-so-poor, raising the latter above the low-income cut-off. 
The low-income rate falls as a result indicating low-income is declining even though the lowincome population is "poorer" (has lower income) than before the transfer, surely a "perverse" result as Sen concluded.

Sen proceeded to outline a number of basic axioms that any low-income/poverty index should satisfy. The monotonicity axiom states that, given other things, a reduction/increase in income of a person below the low-income cut-off must increase/reduce the low-income index. The transfer axiom states that, given other things, a pure transfer of income from a person below the cut-off to anyone who is richer must increase the low-income index (and, vice versa). A low-income or poverty rate does not satisfy these axioms. ${ }^{2}$

The construction of a measure that satisfies these axioms involves creating an index that incorporates all of the information on the distribution of low-income in a population, taking account of the fact that among the "poor" some persons are "poorer" than others. A satisfactory index will go beyond the usual practice of simply classifying the population as "poor" or "not poor" and, instead, measure the intensity of poverty (or low-income) in a population. The insight itself is hardly novel. Statistics Canada routinely supplements information on the low-income rate with information on the "aggregate income deficiency" of low-income families, the average dollar value by which the income of low-income families falls short of their low-income cut-off. The absence of a theoretically-based model for the incorporation of the additional information into a general index of low-income, however, has meant the information is usually ignored in assessing low-income trends. This is in part because of the desire for a single low-income indicator, as noted earlier.

The Sen-Shorrocks-Thon (SST) index developed independently by Thon (1979, 1983) and Shorrocks (1995), and elaborated by Osberg and Xu (1997; 1998) satisfies Sen's axioms in addition to having other desirable statistical properties. The index makes use of all of the information available on the distribution of low-income including the average income shortfall of low-income families as well as the shape of the low-income distribution.

Calculation of the SST index begins with the usual measure of the "low-income gap," the difference ( in dollars) between the low-income line $(Z)$ and actual income of the low-income family $\left(\mathrm{Y}_{i}\right)$ and expresses the gap as a ratio of the low-income line as in:

$$
\text { (1) } \quad \mathrm{X}_{i}=\left(\mathrm{Z}-\mathrm{Y}_{i}\right) / \mathrm{Z}
$$

where $\mathrm{X}_{i}$ is set to zero for the non-poor. In effect, rather than a dichotomy (poor/not poor), lowincome is measured as a continuous variable ranging from zero (for the non-poor) to its empirically observed maximum. As with any variable, the low-income gap ratio can be described in terms of its mean (the average depth of poverty in the population) and the shape of its

2 If one accepts Sen's axioms, the low-income rate is not a valid indicator of low-income. An extreme operationalist would reject this conclusion since the criterion of construct validity is irrelevant. Alternatively, one might define the underlying concept of "low-income" or "poverty" to satisfy an alternative set of axioms so that the "perverse" conclusions highlighted by Sen would not be considered "perverse" at all. To our knowledge, no such alternative set of axioms exist. 
distribution. The Sen-Shorrocks-Thon index of the low-income intensity is a function of the average low-income gap ratio and the Gini coefficient $(\mathrm{G})$ of low-income gap ratios for the entire population as in:

(2) $\quad \mathrm{P}(\mathrm{Y} ; \mathrm{z})=\mu(\mathrm{X})[1+\mathrm{G}(\mathrm{X})]$

where $\mu(\mathrm{X})$ is the mean of the low-income gap ratios for the entire population including the nonpoor. $\mathrm{P}(\mathrm{Y} ; \mathrm{z})$ satisfies the monotonicity and transfer axioms, takes on a values between 0 and 1 , and, analogously to Lorenz curves, can be interpreted as the fraction of the area below the line of maximum low-income (the low-income gap profile obtained when all incomes are zero) filled by the actual low-income gap profile (the cumulative sum of low-income gap ratios after ordering all individuals by the size of their low-income gap from largest to smallest). In this sense, for any given low-income line, $\mathrm{P}(\mathrm{Y} ; \mathrm{z})$ exhausts the information available on the distribution of lowincome in a population.

While the Sen-Shorrocks-Thon index and related measures (e.g. Foster, Greer, Thorbecke, 1984) represent considerable advance in both the theory and measurement of poverty or low-income, neither the theory nor the measures have had much impact on public debate in large measure because such indexes do not have a readily intuitive interpretation. As Osberg and Xu (1997, 1998) show, the mean of $\mathrm{X}_{i}$, i.e., $\mu(\mathrm{X})$, is simply the weighted sum of the average low-income gap ratio among low-income families and the average low-income gap ratio of families not in low-income (i.e. zero) where the weights are the population proportions (i.e. the low-income rate and one minus the low-income rate) so that:

$$
\begin{aligned}
\mu(\mathrm{X}) & =(\text { Rate })(\text { Gap })+(1-\text { Rate })(0) \\
& =(\text { Rate })(\text { Gap })
\end{aligned}
$$

and the SST rewritten as:

$$
\mathrm{P}(\mathrm{Y} ; \mathrm{z})=(\mathrm{RATE})(\mathrm{GAP})[1+\mathrm{G}(\mathrm{X})]
$$

For the purpose of decomposing the intensity measure, it is sometimes useful to express Equation (3) in $\log$ form as:

$$
\ln (\mathrm{P}(\mathrm{Y} ; \mathrm{z}))=\ln (\mathrm{RATE})+\ln (\mathrm{GAP})+\ln (1+\mathrm{G}(\mathrm{X}))
$$

so that the overall change in the index $(\mathrm{P}(\mathrm{Y} ; \mathrm{z}))$ between any two points in time (or between two different population groups or regions), which is written as $\Delta \ln (\mathrm{P}(\mathrm{Y} ; \mathrm{z}))$ can be expressed as the sum of the change in its components as in:

$$
\Delta \ln (\mathrm{P}(\mathrm{Y} ; \mathrm{z}))=\Delta \ln (\mathrm{RATE})+\Delta \ln (\mathrm{GAP})+\Delta \ln (1+\mathrm{G})
$$

Changes in $[1+G(X)]$ account for very little of the change in the overall poverty profile so that, in practice, changes in low-income intensity can be approximated by the product of changes in 
the low-income rate and the average low-income gap ratio of the poor. When the amount of change is not large, a difference in logs is closely approximated by the more familiar percentage change.

In practice, changes in the index are dominated by the first two terms so that changes over time (or differences among populations) can be approximated by:

$$
\% \text { change in intensity }=\% \text { change in the rate }+\% \text { change in the gap }{ }^{3}
$$

This percentage change equation is an approximation of a precise logarithmic identity and is a reasonable approximation when the magnitude of change is small. Because percentage changes are more readily familiar to most readers we will make use of it for much of our analysis, drawing on the more precise logarithmic version of this identity when the percent changes are quite large.

Since the intensity measure captures all of the information on the distribution of low-income (the rate, the average low-income gap, and the shape of its distribution) it will be sensitive to any change in the level or distribution of employment income or transfer payments among lowincome households. ${ }^{4}$ Unlike the absolute dollar value of the low-income gap, the low-income gap ratio is comparable across families and individuals. ${ }^{5}$

While several alternative indices of "poverty intensity" have been available for some time, the Osberg-Xu formulation opens the door for its adoption by policy analysts and social science researchers by showing how an unfamiliar but theoretically desirable quantity - the SST index can be understood in terms of quantities that are familiar (the low-income rate and the low-

3 This equation is an approximation of the precise identity given above in equation (6). The change in the log of any variable is an approximation of the percentage change in that variable. The percentage approximation holds fairly well when the percentage change is small but not when the percentage changes become very large, say over $30 \%$. We have dropped the third term in this approximation because it is usually (although not always) close to zero.

4 Where the line is drawn will matter since any low-income cut-off or poverty line will not register income that exceeds the cut-off but only income that "fills in" a family's low-income/poverty gap. By definition, transfers that exceed a family's low-income gap (as UI benefits frequently do) do not reduce "low-income" or "poverty" so that a higher cut-off will register a larger share of total income transfers than a lower cut-off.

5 Because the low-income gap is expressed as a ratio measure (the gap as a \% of the low-income cut-off), it standardizes this information across families whose low-income cut-offs vary due to adjustments for differences in family size and place of residence. The usual statistical series on the average dollar value of the gap does not make this adjustment and is not comparable across families. Expressing the low-income gap as a ratio of the lowincome line is especially desirable for measures such as the LICO where different cut-offs are calculated depending on family size and size of area of residence. A low-income gap of say \$5000 may represent a lowincome deficit of $20 \%$ in one family and $30 \%$ in another. In contrast, a child in a family that falls $20 \%$ below that family's LICO is equivalent to a child in another family $20 \%$ below the LICO irrespective of differences in the absolute dollar value of the low-income deficit. Just as one can use the LICO to determine the proportion of children in low-income families, a low-income gap ratio enables one to identify the proportion of children in families falling, say, $50 \%$ below the low-income cut-off whereas the absolute low-income gap is not comparable across individuals or families. 
income gap). Information on the distribution of low-income has not been routinely incorporated into assessments of low-income trends with the result, as we will show, that the conclusions drawn are often partial and potentially misleading.

\section{Low-Income Intensity Among Children, 1981-96}

\section{Introduction and Methodological Considerations}

Both labour market conditions and the social transfer system changed significantly over the 1981-96 period. The Canadian economy went through a severe recession in the early 1980s and again in the early 1990s. To isolate trends and control for these cyclical variations during the 1980s, we focus on 1981 and 1989. These end-years are chosen because they are roughly comparable years in terms of the job market. In 1981 the unemployment rate was $7.6 \%$, in 1989 $7.5 \%$.

We then turn our attention to the period of recession (1989-93) and recovery (1993-96). We are especially concerned with identifying the underlying patterns in earnings and social transfers associated with an unexpected increase in low-income after 1993, a period of recovery when one normally expects low-income rates to decline. We first focus on low-income trends, and the extent to which these differ depending on whether they are measured by a traditional rate, or by the intensity measure.

A second issue concerns the sensitivity of a low-income index to changes in transfers or market earnings. In particular, policy-makers and their critics are concerned with measuring the impact of transfers and taxes on low-income families. To measure the effects of transfers on the income distribution requires a counterfactual - what would the distribution be like in the absence of transfers and taxes. We make no attempt at identifying the "real" counterfactual. To do so would require a complex model to take account of the behavioural (second-order) effects of transfers (and taxes) on the distribution of market income. Furthermore, in the policy analysis world such an approach is rarely used, and in this paper we are concerned with altering standard practice. Hence, we follow the usual convention of measuring the "first-order" effects of transfers and taxes by comparing the final distribution of low-income (after transfers/taxes) with the distribution of low-income before transfers and taxes. First-order effects represent the direct (accounting-based) effect of a change in transfer payments or employment earnings on the income of the low-income population. A $\$ 100$ rise in transfer payments is seen as a $\$ 100$ rise in total income and the impact of transfers and taxes on the initial (market) distribution of earnings (e.g. through a work disincentive effect) is ignored.

Data are from the Survey of Consumer Finances (SCF). While the SCF measures the largest share of income quite accurately, particularly employment earnings, it underestimates some components of income, including social assistance and UI, as well as investment income. In the aggregate, between $75 \%$ and $80 \%$ of government transfers are captured by the data source. The result is that the SCF underestimates the impact of transfer payments on low-income for any given year. However, since our concern is primarily with changes through time, we are less 
concerned with this underestimation than if we were focusing on the impact of transfers as of a point-in-time.

Since the mean of the low-income gap ratio is sensitive to extreme cases, the results are calculated only for families with positive incomes. Results are reported to the third digit. The extent to which differences in the third digit are statistically significant is discussed in Osberg and Xu (1997: 27) and Appendix A.

Measurement of low-income requires the choice of a low-income cut-off, a topic that remains highly controversial (Wolfson and Evans, 1989). To determine the sensitivity of our results to the choice of cut-off, we present trends in low-income using four alternative measures; three are variants of the LICO, and one is a LIM-based cut-off (50\% of the median income). The most familiar, and highest, cut-off is Statistics Canada's Low-Income Cut-Off (or LICO) calculated on the basis of total income including market income and transfers but before taxes. Statistics Canada also routinely publishes a less well-known series based on after-tax (disposable) income (the LICO-IAT). The LICO-IAT typically produces low-income rates about 4 percentage points lower than the LICO. ${ }^{6}$ Both measures are rebased from time to time to take account of changes in the distribution of income in order to introduce a "relative" component to the measure. Here, however, we use the 1992 base throughout, effectively treating the LICOs as "absolute" or "fixed" measures of low-income. ${ }^{7}$ The third cut-off employed here is set at $70 \%$ of the LICO (post transfer/pre-tax). This is the lowest cut-off, and is used simply to assess the difference between the rate and intensity analysis when a lower cut-off is used. The cut-offs vary by family size and size of region. To provide the reader with a sense of their magnitudes, the cut-offs for 1996 (and all other years, since a fixed cut-off is used) for a four person family (using the 1992 base) are:

\begin{tabular}{|l|c|c|c|c|c|}
\hline \multicolumn{7}{|c|}{ Region Size (in thousands) } \\
\hline & $\mathbf{5 0 0 +}$ & $\mathbf{1 0 0 - 4 9 9}$ & $\mathbf{3 0 - 9 9}$ & $<\mathbf{3 0}$ & Rural \\
\hline & & & & & \\
LICO & $\$ 32,238$ & 27,651 & 27,459 & 25,551 & 22,279 \\
LICO- IAT & $\$ 27,194$ & 22,907 & 22,552 & 20,608 & 17,829 \\
$70 \%$ of LICO & $\$ 22,567$ & 19,356 & 19,221 & 17,886 & 15,595 \\
\hline
\end{tabular}

Relative low-income measures, in contrast, are constantly adjusted to take account of changes in income levels (reflected by changes in median incomes) and changes in the distribution of incomes. The relative low-income cut-off used here is $50 \%$ of the (after-tax) median income of all Canadians in the reference year. It's value changes annually reflecting changes in median income. We denote the relative low-income measure by LIM-IAT, since it is based on after

6 HRDC's new market-basket measure of poverty produces estimates about 5 percentage points below the LICO.

7 The LICO is fixed at the 1996 levels, based on the 1992 revisions. Earnings are then computed in 1996 constant dollars, and the cut-offs applied to these earnings. The term "absolute" poverty often refers to a living standard below which subsistence becomes difficult if not impossible; hence it remains "fixed" or constant over time since the cut-off is not affected by rising (or falling) real living standards or changes in the distribution of living standards in the population as a whole. The 1992 LICOs qualify as "absolute" measures of low-income only in the sense that they do not account for changes in real living standards (or income), as the LIM does. 
taxes/transfer (disposable) income. ${ }^{8}$ Results for this measure are presented in the appendix and discussed in the text when they differ from the LICO-based findings.

The analysis is conducted for all family types, and reported in the body of the paper. However, trends and the impact of changing transfers or employment earnings may differ between twoparent and lone-parent families. Hence, illustrative results by family type using the LICO-IAT are also reported as appropriate.

Low-income trends indexed by the LICO and the 70\%-LICO are reported on an after-transfer, pre-tax basis. The two IAT measures report low-income after both transfers and taxes.

Our reasons for presenting four sets of results are substantive as well as technical. As noted above, much of the controversy over low-income measurement concerns where and how to draw a low-income-cut-off. Policy-makers are often frustrated by the fact that incremental reforms that genuinely improve the well-being of the very poor but fail to raise their incomes above a cut-off such as the LICO remain statistically invisible. One temptation in this situation is to adopt a lower cut-off in the hope of making such policy changes statistically visible. One of our aims is to show that simply changing the cut-off, whether by raising or lowering it, is unlikely to solve the problem of insensitivity of the measure to change in transfer income (or market earnings) if the resulting low-income (or poverty) rate is used as the yardstick. As noted earlier, additional information on changes in the income gap must be incorporated.

\section{Changes in Transfers, Market Incomes and Low-Income Intensity During the 1980s}

The 1980s were a turbulent period for Canadian wage-earners (Morissette, Myles and Picot, 1994). The early 1980s brought the worst recession since the 1930s (to that time) and important changes were taking place in its aftermath despite recovery later in the decade. There was widespread discussion of a declining middle class in the face of evidence of growing polarization in the distribution of earnings especially among male workers even as the economy was recovering later in the decade. Children were particularly vulnerable to these developments since a major component of change was a real and relative decline in the earnings of younger adults (under 35), the parents of most young children (Picot, Myles, and Pyper, 1998).

8 This LIM-IAT cut-off should be distinguished from a similar low-income measure (LIM) routinely calculated by Statistics Canada. Whereas the usual Statistics Canada estimate is based on median family income, the LIM-IAT used here is based on the median income assigned to all individuals derived after adjusting total family income to reflect differences in family size (Picot and Myles, 1996). Conceptually, the difference is that between a familyweighted (LIM) and a population-weighted (LIM-IAT) social welfare measure. 
Table 1: Changes in Pre-Transfer (Market Earnings) Low-Income Intensity and its Components, Children Aged 0-17, 1981-89

\begin{tabular}{|c|c|c|c|c|c|c|c|c|c|}
\hline & \multicolumn{3}{|c|}{$\begin{array}{c}\text { Low-Income Intensity } \\
\text { LICO }\end{array}$} & \multicolumn{3}{|c|}{$\begin{array}{c}\text { Low-Income Intensity } \\
\text { LICO-IAT }\end{array}$} & \multicolumn{3}{|c|}{$\begin{array}{l}\text { Low-Income Intensity } \\
70 \% \text { of the LICO }\end{array}$} \\
\hline & 1981 & 1989 & Change & 1981 & 1989 & Change & 1981 & 1989 & Change \\
\hline Low & 0.206 & 0.222 & $7.8 \%$ & 0.173 & 0.191 & $10.4 \%$ & 0.155 & 0.173 & $11.6 \%$ \\
\hline Rate & 0.224 & 0.222 & $-0.9 \%$ & 0.1 & 0 . & $4.8 \%$ & 0.141 & 0.149 & $5.7 \%$ \\
\hline & 0.491 & & $9.4 \%$ & 0.543 & 0.578 & $6.4 \%$ & 0.575 & 0.615 & $7.0 \%$ \\
\hline Inequality in the Gap & 1.864 & 1.858 & $-0.3 \%$ & 1.892 & 1.884 & $-0.4 \%$ & 1.907 & 1.898 & $-0.5 \%$ \\
\hline
\end{tabular}

Table 1 shows the change in pre-transfer low-income intensity and its components (the rate, the gap and inequality in the distribution of the gap) calculated on the basis of the three LICO-based cut-offs, the LICO, the LICO-IAT, and the 70\%-LICO cut-off. The lower cut-offs index a lower level of low-income intensity but a larger amount of relative change. The qualitative conclusions are the same, however, irrespective of the cut-off: low-income intensity based on market earnings (employment earnings plus investment income) rose over the decade, from about $8 \%$ to $12 \%$, depending on the measure. Moreover, changes in the low-income rate (registering from a $-1 \%$ to $6 \%$ change) substantially underestimate the total change in low-income intensity since the increase is dominated by trends in the low-income gap. Based on the highest and most commonly used cut-off, the LICO, the rate actually fell slightly, totally obscuring the change as indexed by the intensity measure.

The change in the intensity measure is easily decomposed into that due to changes in the rate, and that due to changes in the gap. This is because the sum of the percentage change in the rate and the gap approximately equals the percentage change in the intensity measure. The third term (inequality in the gap) is usually very small. For example, based on the LICO-IAT, pre-transfer intensity rose $10.4 \%$ over the $1980 \mathrm{~s}$; about $60 \%(6.4 / 10.4)$ of this change was due to changes in the gap, and $45 \%(4.8 / 10.4)$ due to changes in the rate 9

9 This does not add exactly to $100 \%$ for two reasons: (1) the third term is excluded, and there was a small negative change, and (2) the sum of the percentage change is an approximation of the exact identity, which is based on changes in the logs of the rate, gap and inequality of the gap. If "changes in the logs" are used rather than "percentage changes", the identity is exact, and the change in the three components will exactly equal the change in the intensity measure. Percentage changes are used because they are much more familiar to most readers. 
Table 2: Average Income by Source, Families with Children and Market Incomes below the LICO-IAT, 1981 and 1989, by Family Type (1996 Constant \$'s)

\begin{tabular}{|c|c|c|c|c|c|c|}
\hline & $\begin{array}{c}\text { Average } \\
\text { Market } \\
\text { Earnings }\end{array}$ & $\begin{array}{c}\text { Average } \\
\text { Social } \\
\text { Assistance }\end{array}$ & $\begin{array}{c}\text { Average } \\
\text { UI } \\
\text { Benefits }\end{array}$ & $\begin{array}{c}\text { Average } \\
\text { of other } \\
\text { Transfers* }\end{array}$ & $\begin{array}{c}\text { Average } \\
\text { Taxes }\end{array}$ & $\begin{array}{c}\text { Average } \\
\text { Total Transfers } \\
\text { \& Taxes } \\
\text { (transfers minus } \\
\text { taxes) } \\
\end{array}$ \\
\hline \multicolumn{7}{|c|}{$\begin{array}{l}\text { All families with children in } \\
\text { market-based low-income }\end{array}$} \\
\hline 1981 & $\$ 9,690$ & $\$ 2,930$ & $\$ 1,840$ & $\$ 3,430$ & $\$ 480$ & $\$ 7,730$ \\
\hline 1989 & $\$ 9,030$ & $\$ 3,890$ & $\$ 2,280$ & $\$ 4,190$ & $\$ 700$ & $\$ 9,670$ \\
\hline Difference (\$) & $-\$ 660$ & +960 & +440 & +760 & +220 & $+1,940$ \\
\hline$\%$ Change & $-6.8 \%$ & $+32.7 \%$ & $+23.9 \%$ & $+22.1 \%$ & $+45.8 \%$ & $+25.1 \%$ \\
\hline \multicolumn{7}{|c|}{$\begin{array}{l}\text { Two-parent families } \\
\text { with children }\end{array}$} \\
\hline 1981 & $\$ 11,890$ & $\$ 2,170$ & $\$ 2,290$ & $\$ 3,860$ & $\$ 612$ & $\$ 7,710$ \\
\hline 1989 & $\$ 11,560$ & $\$ 2,820$ & $\$ 3,010$ & $\$ 4,800$ & $\$ 995$ & $\$ 9,636$ \\
\hline Difference (\$) & $-\$ 330$ & +650 & +720 & +940 & +383 & $+1,926$ \\
\hline$\%$ Change & $-2.8 \%$ & $+30.0 \%$ & $+31.4 \%$ & $+24.3 \%$ & $+62.5 \%$ & $+24.9 \%$ \\
\hline \multicolumn{7}{|c|}{ Lone-parent families } \\
\hline 1981 & $\$ 4,040$ & $\$ 4,890$ & $\$ 680$ & $\$ 2,340$ & $\$ 140$ & $\$ 7,770$ \\
\hline 1989 & $\$ 4,470$ & $\$ 5,800$ & $\$ 980$ & $\$ 3,110$ & $\$ 170$ & $\$ 9,720$ \\
\hline Difference (\$) & $\$ 430$ & +910 & +300 & +770 & +30 & $+1,950$ \\
\hline$\%$ Change & $10.6 \%$ & $+18.6 \%$ & $+44.1 \%$ & $+32.9 \%$ & $+21.4 \%$ & $+25.1 \%$ \\
\hline
\end{tabular}

* Including family allowances, provincial tax credits, child tax benefits, GST credit, workers compensation, other government income.

The rise in low-income intensity before transfers reflects the fact that average employment earnings fell among most low-income families. For illustrative purposes, we choose families with children whose market earnings were below the LICO-IAT (the middle cut-off), children at risk of being in low-income before transfers. Market earnings (mainly employment) in these families fell by an average $\$ 660$ or about 7 percent (Table 2). However, average transfers (after taxes) rose by almost $\$ 2000$ (a 25 percent gain), reflecting an average increase of $\$ 960$ in social assistance benefits, $\$ 760$ in other family transfers and $\$ 440$ in UI benefits. The result was a net gain of approximately $\$ 1300$ in average disposable income among families at risk. 
Table 3: Changes in Low-Income Intensity and its Components, Children Aged 0-17, after Transfers/Taxes, ${ }^{10}$ 1981-89

\begin{tabular}{|c|c|c|c|c|c|c|c|c|c|}
\hline & \multicolumn{3}{|c|}{$\begin{array}{c}\text { Low-Income Intensity } \\
\text { LICO Cut-Off }\end{array}$} & \multicolumn{3}{|c|}{$\begin{array}{l}\text { Low-Income Intensity } \\
\text { LICO-IAT Cut-Off }\end{array}$} & \multicolumn{3}{|c|}{$\begin{array}{l}\text { Low-Income Intensity } \\
70 \% \text { of the LICO Cut-Off }\end{array}$} \\
\hline & 1981 & 1989 & Change & 1981 & 1989 & Change & 1981 & 1989 & Change \\
\hline Lov & 0.1 & 0.095 & $-11.2 \%$ & 0.076 & 0.064 & $-15.8 \%$ & 0.054 & 0.042 & $-22.2 \%$ \\
\hline Rate & 0.164 & 4 & $-6.1 \%$ & 0.124 & 0.119 & $-4.0 \%$ & 0.086 & 0.079 & $-8.1 \%$ \\
\hline & 0.344 & 3 & $-6.1 \%$ & 0.317 & 0.278 & $-12.3 \%$ & 0.324 & 0.268 & $-17.3 \%$ \\
\hline Inequality in the Gap & 1.899 & 1.901 & $0.1 \%$ & 1.928 & 1.929 & $0.1 \%$ & 1.950 & 1.953 & $0.2 \%$ \\
\hline
\end{tabular}

What impact did rising transfers have on low-income levels among Canadian children? The answer, when the low-income rate is the yardstick, is not much (Table 3, Row 2). The social transfer system produced real gains in reducing low-income intensity over the decade (in the order of $11 \%$ to $22 \%$ depending on the choice of cut-off), gains that are largely obscured by changes in the low-income rate. The (post-transfer) LICO rate fell by $6 \%$, capturing about half of the total improvement in low-income intensity. But, strikingly, moving the goal-posts from a higher to a lower cut-off makes the rates less sensitive to the change. Changes in the lower rates (LICO-IAT and the 70\%-LICO) captured about one third of the total change, changes that would not usually be considered statistically significant.

The conclusion we, and others, have reported in past research (Picot and Myles, 1996; Picot, Myles and Pyper, 1998), based on changes in the rates, that low-income among children did not change through the 1980s after transfers is misleading. These results, based on changes in the relative (LIM-IAT) low-income rate, are replicated in Appendix Table B-1. If anything, changes in the relative low-income rate were even a poorer guide to the underlying change in the distribution of low-income. The LIM-IAT rate stood at 11.4 percent in 1981 and 11.1 percent in 1989 , a relative decline of only $2.6 \%$, in period when relative low-income intensity fell by almost $15 \%$.

The reason for these differences, of course, is that during the 1980s changes in low-income intensity were dominated by changes in the low-income gap: from one-half to three quarters of the change in low-income intensity was due to changes in the gap (depending on the measure). Low-income families with children were somewhat less poor at the end of the decade than at the beginning. Moreover, the gains were largest among the very poorest families, a result reflected in the fact that reductions in the low-income gap are substantially larger when measured by the lower cut-offs. The average LICO gap fell slightly from $34 \%$ to $32 \%$ (a relative change of only $6 \%$ ). In contrast the $70 \%$-LICO gap fell from $32 \%$ to $27 \%$ (a relative change of 17 percent).

${ }_{10}$ Changes to low-income intensity based on the LICO and 70\%-LICO are after transfers, while changes to lowincome intensity based on LICO-IAT are after both taxes and transfers. 
Table 4: Low-Income Intensity and its Components, Children Under 18, 1981 and 1989 (Based on After Taxes/Transfer LICO), by Family Type

\begin{tabular}{|c|c|c|c|}
\hline & 1981 & 1989 & \% Change 1981-1989 \\
\hline \multicolumn{4}{|l|}{ All children } \\
\hline a) Market-income based measure & & & \\
\hline Low-income intensity & 0.183 & 0.199 & $8.7 \%$ \\
\hline Low-income rate & 0.171 & 0.177 & $3.5 \%$ \\
\hline Low-income gap & 0.564 & 0.595 & $5.5 \%$ \\
\hline Gini for the gap & 0.892 & 0.885 & $-0.7 \%$ \\
\hline b) Measured after taxes/transfers & & & \\
\hline Low-income intensity & 0.086 & 0.071 & $-17.4 \%$ \\
\hline Low-income rate & 0.127 & 0.121 & $-4.7 \%$ \\
\hline Low-income gap & 0.352 & 0.306 & $-13.1 \%$ \\
\hline Gini for the gap & 0.930 & 0.932 & $+0.2 \%$ \\
\hline \multicolumn{4}{|l|}{ Children in two-parent families } \\
\hline a) Market-income based measure & & & \\
\hline Low-income intensity & 0.124 & 0.124 & $0.0 \%$ \\
\hline Low-income rate & 0.137 & 0.132 & $-3.6 \%$ \\
\hline Low-income gap & 0.470 & 0.491 & $+4.5 \%$ \\
\hline Gini for the gap & 0.916 & 0.919 & $+0.3 \%$ \\
\hline \multicolumn{4}{|l|}{ b) Measured after taxes/transfers } \\
\hline Low-income intensity & 0.053 & 0.042 & $-20.8 \%$ \\
\hline Low-income rate & 0.095 & 0.081 & $-14.8 \%$ \\
\hline Low-income gap & 0.285 & 0.267 & $-6.3 \%$ \\
\hline Gini for the gap & 0.946 & 0.953 & $+0.7 \%$ \\
\hline \multicolumn{4}{|l|}{ Children in single parent families } \\
\hline a) Market-income based measure & & & \\
\hline Low-income intensity & 0.687 & 0.704 & $+2.5 \%$ \\
\hline Low-income rate & 0.578 & 0.608 & $+5.2 \%$ \\
\hline Low-income gap & 0.774 & 0.764 & $-1.3 \%$ \\
\hline Gini for the gap & 0.536 & 0.513 & $-4.3 \%$ \\
\hline b) Measured after taxes/transfers & & & \\
\hline Low-income intensity & 0.340 & 0.248 & $-27.1 \%$ \\
\hline Low-income rate & 0.509 & 0.497 & $-2.4 \%$ \\
\hline Low-income gap & 0.398 & 0.296 & $-25.6 \%$ \\
\hline Gini for the gap & 0.678 & 0.687 & $+1.3 \%$ \\
\hline
\end{tabular}


Results by family type (Table 4) shed additional light on these differences. Once again, we use results based on the LICO-IAT to illustrate our conclusions. Lone parents were disproportionately affected by higher social assistance benefits, the largest source of rising transfers during the eighties (Table 2). Not surprisingly, then, the single largest change over the decade was a large decline in low-income intensity among children in lone parent families (from .34 to .25). This change was almost entirely the result of a correspondingly large decline in the low-income gap among these children (from .40 to .30). Their low-income rate, in contrast, changed little.

In short, the largest gains over the 1980s were made by lone-parent families who on average are much poorer than two-parent families. Since rising transfers were disproportionately targeted on families with the greatest need, the reduction in the low-income gap is much larger when measured against the lower of the low-income cut-offs. As we will see shortly, however, the converse is also true. During periods when transfers to low-income families are falling, as they did between 1993 and 1996, the lower cut-offs also register a proportionately larger increase in low-income intensity.

It is important to be clear, however, about the methodological implications of this result. Lowincome intensity measured by the lower cut-offs was more sensitive to change over this particular period because of the particular way in which the low-income distribution was changing. It does not follow that this will always be so. As we report below, the recession of 1989-93 had its largest impact on children in two-parent families, households that normally have significant earnings and in this period the higher cut-offs register the largest change.

Nor does it follow that a low-income rate calculated with a lower cut-off will be any more or less sensitive to changes in social transfers (or vice versa). We can gauge the relative contribution of changing earnings and changing transfers in generating these results by comparing changes in low-income intensity before and after transfers/taxes (Table 5). We use the "disposable income" based LICO, the LICO-IAT, to demonstrate this point (Table 5).

Table 5: Low-income Intensity (LICO-IAT base), Children 0-17, 1981-89

\begin{tabular}{|c|c|c|c|c|c|c|c|}
\hline & \multicolumn{3}{|c|}{ Before Transfers } & \multicolumn{3}{|c|}{ After Transfers/Taxes } & \multirow[b]{2}{*}{$\begin{array}{l}\text { Difference } \\
(3)-(6)\end{array}$} \\
\hline & $\begin{array}{c}1981 \\
(1)\end{array}$ & $\begin{array}{c}1989 \\
(2)\end{array}$ & $\begin{array}{c}\text { \% Change } \\
\text { (3) }\end{array}$ & $\begin{array}{l}1981 \\
(4)\end{array}$ & $\begin{array}{c}1989 \\
(5)\end{array}$ & $\begin{array}{c}\text { \% Change } \\
(6)\end{array}$ & \\
\hline Low-Income Intensity & 0.173 & 0.191 & $10.40 \%$ & 0.076 & 0.064 & $-15.80 \%$ & $26.20 \%$ \\
\hline Rate & 0.168 & 0.176 & $4.80 \%$ & 0.124 & 0.119 & $-4.00 \%$ & $8.80 \%$ \\
\hline Gap & 0.543 & 0.578 & $6.40 \%$ & 0.317 & 0.278 & $-12.30 \%$ & $18.70 \%$ \\
\hline Inequality in the Gap & 1.892 & 1.884 & $-0.40 \%$ & 1.928 & 1.929 & $0.10 \%$ & $-0.50 \%$ \\
\hline
\end{tabular}

Before taxes/transfers, low-income intensity rose 10 percent over the $1980 \mathrm{~s}$; after taxes/transfers it fell by $16 \%$. If the effect ${ }^{11}$ of the tax/transfers system on reducing low-income had remained constant throughout the $1980 \mathrm{~s}$, then the change in the low-income intensity index would have been the same before and after taxes/transfers. That is, both would have risen by roughly 10

11 The "first-order" effect (in an accounting sense) ignoring behavioral response and any work disincentive effect. 
percent. The reason can be seen in Figure 1. In the chart in panel A, transfers would have reduced the level of low-income by the same amount over the entire period, resulting in two parallel lines, before and after taxes/transfers. Both lines would have increased by roughly the same amount ${ }^{12}$. But this did not occur during the 1980s. Low-income intensity before taxes/transfers rose, while after it fell, more closely resembling the hypothetical example in panel B. In this case, the effect of the transfer system on low-income was increasing. The difference in the percentage change before and after transfers is used as an indication of the change in the effect of the tax/transfer system on low-income intensity. This is shown in Table 5. As noted, low-income rose 10 percent before taxes/transfers, and fell 16 percent after. The difference $(10.4-(-15.8)=26.2)$ is an indication of the change in the effect of the tax transfers system on low-income intensity between 1981 and 1989. The large value indicates that the transfer system increasingly reduced lowincome intensity over the 1980s. Furthermore, this effect can be decomposed into the extent to which it was reflected in the rate, and in the gap. In this case, only about one-third of the increased effect of the transfer system on low-income was seen in the rate (8.8/26.2. Table 5). The tax/transfer system was increasingly offsetting low-income among children during the 1980s, but most of this increased impact was reflected in the change in the gap, not in the rate.

\section{Figure 1: Hypothetical Low-Income Intensity}

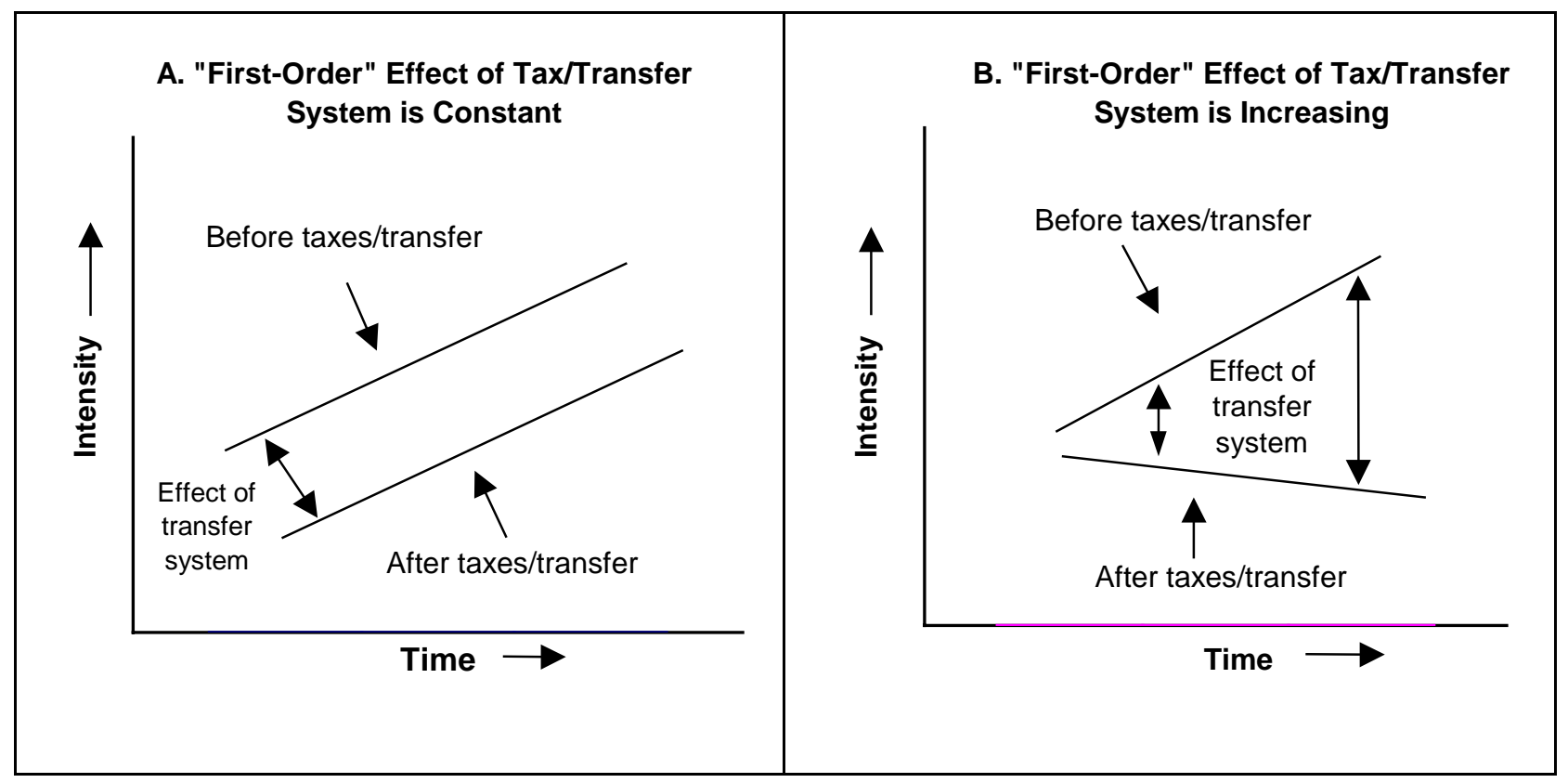

12 In this graphical example the increase would have been the same in terms of "level", but the percentage increase would have been slightly higher for the after tax/transfer line because it is starting from a lower base. One can choose to use either change in "level" or "growth rate" as the indicator of the change in the effect of the transfer system. We chose the "growth rate" approach because it is consistent with the normally used practice of focusing on the percentage reduction in the low-income rate before and after transfers (see appendix C), and more importantly, because it results in the effect of the transfer system on low-income intensity being decomposable into the effect on the rate, and the effect on the gap. We use the "level" approach in graph 1 simply because of the ease of presentation. 
In sum, trends in low-income rates were a poor guide to changes in the distribution of lowincome during the 1980s irrespective of the cut-off used and failed to register most of the impact of both falling employment earnings and significantly higher social transfers. Low-income rates based on lower cut-offs were no more effective at registering the impact of rising transfers than those based on higher cut-offs. In contrast, the underlying trend and the impact of both falling employment earnings and rising transfers were captured by the low-income intensity measure, irrespective of the level at which the cut-off was placed.

\section{Recession and Recovery, 1989-96}

Earnings and employment levels peaked in 1989 and then declined substantially through 1993 rising slowly thereafter. These trends are reflected in patterns of market-based low-income intensity, which increased quite dramatically between 1989 and 1993 (by 45\% to 54\%, depending on the cut-off) and then declined somewhat between 1993 and 1996 (by around 5\%). In both periods, changes in low-income intensity are dominated by changes in the low-income rate, which accounted for roughly $80 \%$ of the change in the intensity measure.

Table 6: Changes in Pre-Transfer (Market Earnings) Low-Income Intensity and its Components, Children Age 0-17, 1989, 1993, 1996

\begin{tabular}{|c|c|c|c|c|c|}
\hline & \multicolumn{5}{|c|}{$\begin{array}{c}\text { Low-Income Intensity } \\
\text { LICO }\end{array}$} \\
\hline & 1989 & 1993 & 1996 & Change 89-93 & Change 93-96 \\
\hline $\begin{array}{l}\text { Low-Income Intensity } \\
\text { Rate } \\
\text { Gap } \\
\text { Inequality in the Gap }\end{array}$ & $\begin{array}{l}0.222 \\
0.222 \\
0.537 \\
1.858 \\
\end{array}$ & $\begin{array}{l}0.323 \\
0.303 \\
0.593 \\
1.796 \\
\end{array}$ & $\begin{array}{l}0.309 \\
0.291 \\
0.587 \\
1.806 \\
\end{array}$ & $\begin{array}{r}45.5 \% \\
36.5 \% \\
10.4 \% \\
-3.3 \% \\
\end{array}$ & $\begin{array}{r}-4.3 \% \\
-4.0 \% \\
-1.0 \% \\
0.6 \% \\
\end{array}$ \\
\hline & \multicolumn{5}{|c|}{$\begin{array}{c}\text { Low-Income Intensity } \\
\text { LICO-IAT }\end{array}$} \\
\hline & 1989 & 1993 & 1996 & Change 89-93 & Change 93-96 \\
\hline $\begin{array}{l}\text { Low-Income Intensity } \\
\text { Rate } \\
\text { Gap } \\
\text { Inequality in the Gap }\end{array}$ & $\begin{array}{l}0.191 \\
0.176 \\
0.578 \\
1.884 \\
\end{array}$ & $\begin{array}{l}0.289 \\
0.251 \\
0.629 \\
1.826 \\
\end{array}$ & $\begin{array}{l}0.277 \\
0.241 \\
0.627 \\
1.833 \\
\end{array}$ & $\begin{array}{r}51.3 \% \\
42.6 \% \\
8.8 \% \\
-3.1 \% \\
\end{array}$ & $\begin{array}{r}-4.2 \% \\
-4.0 \% \\
-0.3 \% \\
0.4 \% \\
\end{array}$ \\
\hline \multirow{2}{*}{ Inequality in the Gap } & \multicolumn{5}{|c|}{$\begin{array}{l}\text { Low-Income Intensity } \\
70 \% \text { of the LICO }\end{array}$} \\
\hline & 1989 & 1993 & 1996 & Change 89-93 & Change 93-96 \\
\hline $\begin{array}{l}\text { Low-Income Intensity } \\
\text { Rate } \\
\text { Gap } \\
\text { Inequality in the Gap }\end{array}$ & $\begin{array}{l}0.173 \\
0.149 \\
0.615 \\
1.898 \\
\end{array}$ & $\begin{array}{l}0.267 \\
0.222 \\
0.653 \\
1.843 \\
\end{array}$ & $\begin{array}{l}0.254 \\
0.211 \\
0.650 \\
1.851 \\
\end{array}$ & $\begin{array}{r}54.3 \% \\
49.0 \% \\
6.2 \% \\
-2.9 \% \\
\end{array}$ & $\begin{array}{r}-4.9 \% \\
-5.0 \% \\
-0.5 \% \\
0.4 \% \\
\end{array}$ \\
\hline
\end{tabular}


Table 7: Average Income by Source for Families with Children and Market Incomes Below the LICO-IAT, 1989, 1993, 1996 by Family Type (1996 Constant \$)

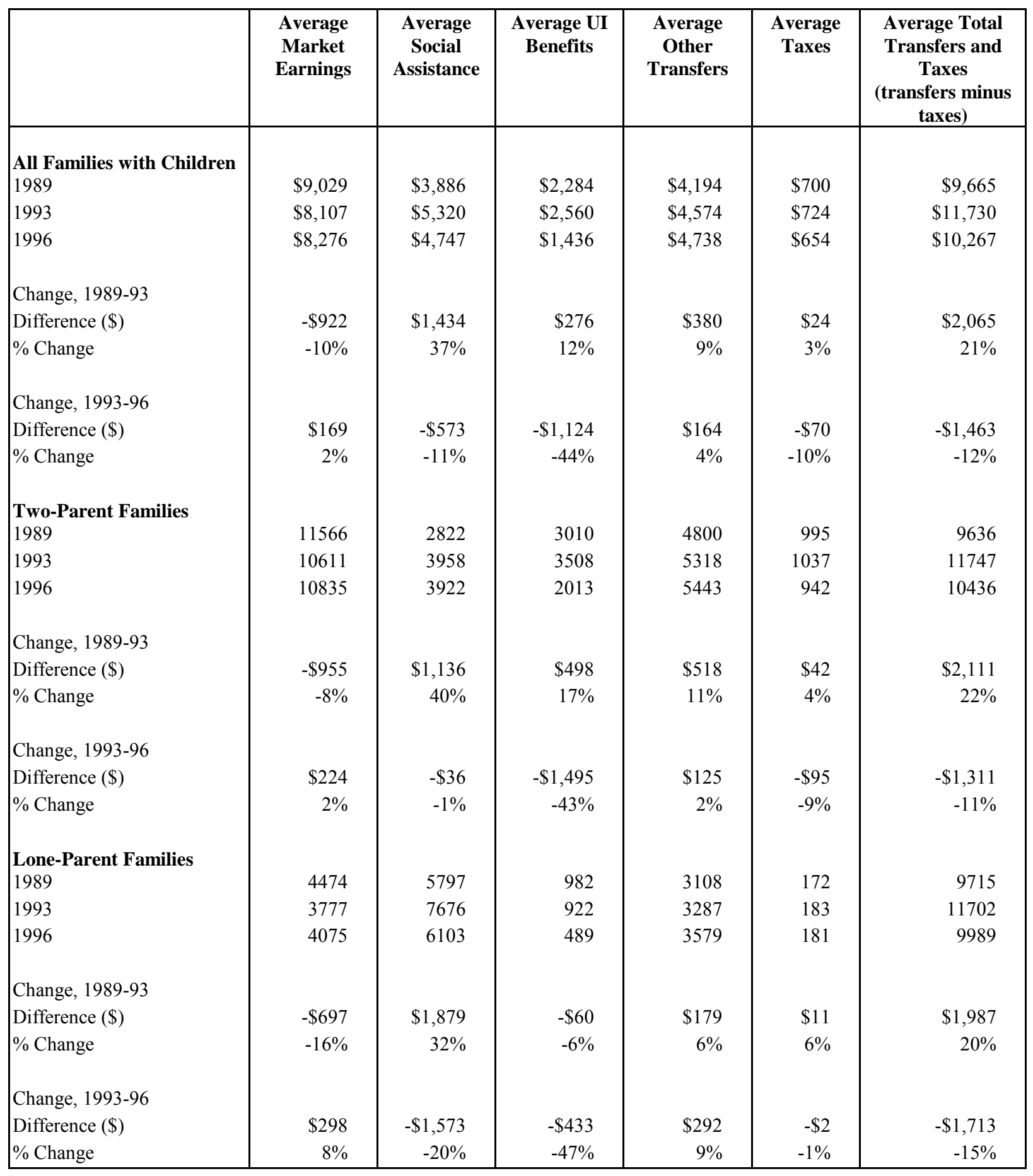


Transfers to low-income families with children (Table 7) rose substantially through 1993 (by about 20 percent) but then declined (by about 12 percent) between 1993 and 1996, as one might expect at this stage in the cycle. However, while average benefit increases (about \$2000) in the $1989-93$ period more than offset the decline in average earnings per family $(-\$ 1000)$, benefit reductions after $1993(-\$ 1500)$ were much larger than the rise in average employment earnings (\$200). Benefit reductions after 1993 were mainly reflected in falling UI benefits in two-parent families and declining social assistance benefits in single parent families.

Rising transfers between 1989 and 1993 considerably muted the impact of recession. Whereas low-income intensity before transfers rose by 45 to $50 \%$, (Table 6), after transfers the increase was about $30 \%$ on the LICO-based intensity measures (Table 8 ). And as the LIM-IAT results (Appendix B-5) show, low-income intensity measured in relative terms actually declined somewhat. ${ }^{13}$ After 1993, low-income intensity before transfers fell somewhat (by 4-5\%) as employment opportunities improved, but a substantial decline in transfers received, for whatever reason, (much greater than the rise in employment earnings) contributed to a significant rise in low-income intensity after taxes and transfers on all measures. Low-income intensity in 1996 based on the LICO-IAT was $20 \%$ above the highest level observed during the 1990 s recession, and fully $50 \%$ above the level observed at the peak of the last business cycle, 1989 (Table 9). Qualitatively the results are the same for the LICO although the increase in intensity is not as great. The ways in which the different indicators of low-income respond to change over the two periods are worth highlighting.

13 Low-income intensity based on a "fixed" cut-off is unlikely to remain stable during a recession without fairly dramatic policy interventions. For this to occur, all earnings losses experienced by people below the cut-off would have to be offset by transfer payments. Since the income of individuals above the cut-off are also falling, this would require policies that substantially raise the low-income population's share of total income, thereby sharply reducing inequality in disposable income. The same is not true when a relative measure is used. If inequality does not change much, then "relative" low-income intensity could remain constant. The transfer system does not have to replace all lost earnings to achieve a constant "relative" low-income intensity. 
Table 8: Changes in Low-Income Intensity and its Components, Children Age 0-17, After Transfers and Taxes, 1989, 1993, 1996

\begin{tabular}{|c|c|c|c|c|c|}
\hline & \multicolumn{5}{|c|}{$\begin{array}{c}\text { Low-Income Intensity } \\
\text { LICO }\end{array}$} \\
\hline & 1989 & 1993 & 1996 & Change 89-93 & Change 93-96 \\
\hline Low-Income Intensity & 0.095 & 0.124 & 0.137 & $30.5 \%$ & $10.5 \%$ \\
\hline Rate & 0.154 & 0.212 & 0.211 & $37.7 \%$ & $-0.5 \%$ \\
\hline Gap & 0.323 & 0.312 & 0.349 & $-3.4 \%$ & $11.9 \%$ \\
\hline \multirow[t]{3}{*}{ Inequality in the Gap } & 1.901 & 1.865 & 1.862 & $-1.9 \%$ & $-0.2 \%$ \\
\hline & \multicolumn{5}{|c|}{$\begin{array}{c}\text { Low-Income Intensity } \\
\text { LICO-IAT }\end{array}$} \\
\hline & 1989 & 1993 & 1996 & Change 89-93 & Change 93-96 \\
\hline Low-Income Intensity & 0.064 & 0.082 & 0.099 & $28.1 \%$ & $20.7 \%$ \\
\hline Rate & 0.119 & 0.158 & 0.172 & $32.8 \%$ & $8.9 \%$ \\
\hline Gap & 0.278 & 0.274 & 0.304 & $-1.4 \%$ & $10.9 \%$ \\
\hline \multirow[t]{3}{*}{ Inequality in the Gap } & 1.929 & 1.905 & 1.895 & $-1.2 \%$ & $-0.5 \%$ \\
\hline & \multicolumn{5}{|c|}{$\begin{array}{c}\text { Low-Income Intensity } \\
70 \% \text { of the LICO }\end{array}$} \\
\hline & 1989 & 1993 & 1996 & Change 89-93 & Change 93-96 \\
\hline Low-Income Intensity & 0.042 & 0.052 & 0.066 & $23.8 \%$ & $26.9 \%$ \\
\hline Rate & 0.079 & 0.105 & 0.121 & $32.9 \%$ & $15.2 \%$ \\
\hline Gap & 0.268 & 0.255 & 0.285 & $-4.9 \%$ & $11.8 \%$ \\
\hline Inequality in the Gap & 1.953 & 1.940 & 1.929 & $-0.7 \%$ & $-0.6 \%$ \\
\hline
\end{tabular}

Table 9: Low-Income Intensity and Its Components, Children Aged 0-17, 1989 to 1996, Based on Both the LICO and LICO-IAT

\begin{tabular}{|l|l|l|l|l|l|l|l|l|}
\hline & \multicolumn{9}{|c|}{ LICO - IAT } \\
\cline { 2 - 10 } & $\mathbf{1 9 8 9}$ & $\mathbf{1 9 9 0}$ & $\mathbf{1 9 9 1}$ & $\mathbf{1 9 9 2}$ & $\mathbf{1 9 9 3}$ & $\mathbf{1 9 9 4}$ & $\mathbf{1 9 9 5}$ & $\mathbf{1 9 9 6}$ \\
\hline & & & & & & & & \\
Low-Income Intensity & 0.064 & 0.077 & 0.081 & 0.077 & 0.082 & 0.080 & 0.090 & 0.099 \\
Rate & 0.119 & 0.133 & 0.145 & 0.142 & 0.158 & 0.148 & 0.165 & 0.172 \\
Gap & 0.278 & 0.300 & 0.293 & 0.284 & 0.274 & 0.282 & 0.287 & 0.304 \\
Inequality in the Gap & 0.929 & 0.920 & 0.912 & 0.916 & 0.905 & 0.910 & 0.901 & 0.895 \\
\hline & \multicolumn{8}{|c|}{ LICO } \\
\cline { 2 - 10 } & $\mathbf{1 9 8 9}$ & $\mathbf{1 9 9 0}$ & $\mathbf{1 9 9 1}$ & $\mathbf{1 9 9 2}$ & $\mathbf{1 9 9 3}$ & $\mathbf{1 9 9 4}$ & $\mathbf{1 9 9 5}$ & $\mathbf{1 9 9 6}$ \\
\hline & \multicolumn{10}{|c|}{} & & & & & & & \\
Low-Income Intensity & 0.095 & 0.111 & 0.117 & 0.115 & 0.124 & 0.118 & 0.130 & 0.137 \\
Rate & 0.154 & 0.178 & 0.188 & 0.190 & 0.212 & 0.193 & 0.210 & 0.211 \\
Gap & 0.323 & 0.331 & 0.332 & 0.321 & 0.312 & 0.326 & 0.332 & 0.349 \\
Inequality in the Gap & 0.901 & 0.889 & 0.880 & 0.881 & 0.865 & 0.875 & 0.865 & 0.862 \\
\hline
\end{tabular}


Lower vs Higher Cut-Offs. Low-income intensity as indexed by the LICO-based cut-offs grew in both periods. However, in 1989-93 the increase is magnified by the higher cut-offs while in 1993-96 the lower cut-offs register the largest gain. Variable sensitivity to the choice of cut-off level simply reflects differences in where in the low-income distribution change is taking place. A lower cut-off is more sensitive to changes concentrated among the very poor and a higher cutoff to changes among the not-so-poor. The main impact of the recession (falling earnings) of the early nineties was on families somewhat higher in the income distribution, two-parent families who normally would have significant employment earnings among whom low-income intensity rose $31 \%$ (Table 10). The recession had relatively little effect on poorer, lone-parent, families that rely mainly on social transfers for their income (intensity fell $2 \%$ ). In contrast, social transfer cuts after 1993 had a somewhat larger impact on the poorer lone-parent families, as low-income intensity rose $25 \%$, compared to $18 \%$ among children in two-parent families.

Low-Income Intensity: The Rate vs the Gap. During 1989-93, the increase is entirely a result of change in the low-income rate while during 1993-96 most of the change is in the low-income gap (Table 8). Indeed, the familiar LICO rate almost totally obscures the impact of falling transfers between 1993 and 1996, much as it obscured the impact of rising transfers in the 1980s. Changes in the relative (LIM-IAT) low-income rate (Appendix Table B-5) are even more misleading, rising in 1989-93 when relative low-income intensity was falling as a result of a substantial fall in the relative low-income gap.

Table 10: Change in After Tax/Transfer Low-Income Intensity and its Components, (LICO-IAT), Children 0-17, by Family Type, 1989, 1993 and 1996

\begin{tabular}{|l|c|c|c|c|c|}
\hline \multirow{2}{*}{} & \multicolumn{5}{|c|}{ Two-Parent Families } \\
\cline { 2 - 6 } & $\mathbf{1 9 8 9}$ & $\mathbf{1 9 9 3}$ & $\mathbf{1 9 9 6}$ & Change 89-93 & Change 93-96 \\
\hline \multirow{2}{*}{ Low-Income Intensity } & 0.042 & 0.055 & 0.065 & $31.0 \%$ & $18.2 \%$ \\
Rate & 0.081 & 0.109 & 0.116 & $34.6 \%$ & $6.4 \%$ \\
Gap & 0.267 & 0.262 & 0.287 & $-1.9 \%$ & $9.5 \%$ \\
Inequality in Gap & 1.953 & 1.936 & 1.931 & $-0.9 \%$ & $-0.3 \%$ \\
\hline \multicolumn{7}{|c|}{ Single-Parent Families } \\
\cline { 2 - 6 } & $\mathbf{1 9 8 9}$ & $\mathbf{1 9 9 3}$ & $\mathbf{1 9 9 6}$ & Change 89-93 & Change 93-96 \\
\hline \multirow{2}{*}{ Low-Income Intensity } & 0.248 & 0.242 & 0.303 & $-2.4 \%$ & $25.2 \%$ \\
Rate & 0.497 & 0.490 & 0.563 & $-1.4 \%$ & $14.9 \%$ \\
Gap & 0.296 & 0.292 & 0.329 & $-1.4 \%$ & $12.7 \%$ \\
Inequality in Gap & 1.687 & 1.693 & 1.634 & $0.4 \%$ & $-3.5 \%$ \\
\hline
\end{tabular}

What was the relative contribution of changes in earnings and social transfers in producing these trends? We use the LICO-IAT cut-off to focus on this question (Table 11). Because the changes in this period are quite large, the amount of error in the percentage change approximation (of the change in logs) for estimating (first-order) effects of transfers/taxes is also large. Accordingly, in Table 11, we report results from the decomposition based on the change in the logarithm of the rate and gap (rather than percentage changes). During the recession of the early nineties, rising transfers offset a non-trivial share of the increase in low-income intensity. Like the eighties, the main impact of higher transfers was on the low-income gap so that comparisons of the change in 
the low-income rates before and after transfers capture less than half of the change (i.e. .072/.166 in Table 11). Between 1993 and 1996, with transfers falling faster than earnings rose, the tendency of transfers to reduce low-income declined. Low-income intensity fell by approximately $4.1 \%$ (Table 11 ) before taxes/transfers, but rose $18.8 \%$ after, indicating a decreasing effect of taxes/transfers on low-income intensity over the period. This decline in the role of transfers was reflected roughly equally in the rate $(.126 / .230)$ and the gap $(.107 / .230)$.

Table 11: Change in $\mathrm{Ln}^{14}$ of Low-income Intensity (LICO-IAT Base) Before and After Transfers and Taxes, 1989-93 and 1993-96

\begin{tabular}{|c|c|c|c|c|c|c|}
\hline & \multicolumn{3}{|c|}{$1989-93$} & \multicolumn{3}{|c|}{ 1993-96 } \\
\hline & $\begin{array}{c}\text { Before } \\
\text { Transfers }\end{array}$ & $\begin{array}{c}\text { After } \\
\text { Transfers/ } \\
\text { Taxes } \\
\end{array}$ & Difference & $\begin{array}{c}\text { Before } \\
\text { Transfers }\end{array}$ & $\begin{array}{c}\text { After } \\
\text { Transfers/ } \\
\text { Taxes } \\
\end{array}$ & Difference \\
\hline & (1) & $(2)$ & (1)-(2) & (1) & (2) & (1)-(2) \\
\hline Low-Income Intensity & 0.414 & 0.248 & 0.166 & -0.042 & 0.188 & -0.230 \\
\hline Rate & 0.355 & 0.283 & 0.072 & -0.041 & 0.085 & -0.126 \\
\hline Gap & 0.085 & -0.014 & 0.099 & -0.003 & 0.104 & -0.107 \\
\hline Inequality in the Gap & -0.031 & -0.013 & -0.018 & 0.004 & -0.005 & 0.009 \\
\hline
\end{tabular}

\section{Conclusion}

Statistics Canada's low-income cut-offs, introduced by Jenny Podoluk (1967) over a quarter century ago, were a source of controversy from the outset (Senate of Canada, 1971; Adams et al., 1971) and the debate is unlikely to go away.

One source of controversy concerns where to draw the low-income cut-off. The choice of higher vs lower cut-offs matters a great deal. A relatively high cut-off (like the LICO) will be rather insensitive to falling (or rising incomes) among the very poorest of the poor. A lower cut-off will be less sensitive to changes among families somewhat higher in the income distribution who are just getting by in good times but whose lives are disrupted in bad times as a result, say, of rising unemployment. This is not news. Low-income researchers have always been aware of the sensitivity of their results to the choice of cut-off levels and "best practise" suggests that checking the sensitivity of results to the choice of cut-off is always in order before drawing conclusions.

Even the most careful analysis, however, will be of limited help in detecting changes in social transfers or labour market earnings among low-income families if the low-income rate is the only yardstick for measuring change. This is true irrespective of the choice of higher vs lower cut-offs or relative vs absolute standards. In the 1980s, for example, rising transfers disproportionately benefitted the poorest of the low-income population and this fact was apparent in the analyses of low-income intensity: low-income intensity measured by the LICO cut-off fell $11 \%$, by the lower LICO-IAT by $16 \%$, and by the yet lower $70 \%$-LICO by $22 \%$. Changes in the corresponding low-income rates, however, picked up little of this effect (declining by only 4\% to 8\%). Conversely, falling transfers after 1993 also had an impact on the economic welfare of Canadian

14 An approximation of the percentage change when the percentage changes are not large. 
children, a result that was only marginally visible (in 1995 and 1996) when measured by the LICO rate alone.

Redistribution is now a core function of government. Assessing the impact of government transfers (and taxes) on those in the lower end of the income distribution occupies a prominent, and no doubt permanent, place in these discussions. As we have emphasized, identification of the "true" counterfactual - what would have happened in the absence of, or under a different, taxtransfer system - is a complex task that lies well beyond the scope of this paper. Nevertheless, a useful "first-order" accounting of the changes underlying low-income trends is a necessary first step. Typically, when there is a sharp or unexpected change in low-income rates we want to know "why"? Have the earnings at the lower end of the income distribution fallen (or risen)? Have transfers? The usual procedure of comparing low-income rates before and after transfers is not up to the task of addressing such questions, even descriptively.

Policy analysts and those who study income distributions have always been aware of the need to supplement information on low-income rates with additional information on the sources and levels of income among the low-income population. The recent developments in low-income measurement that we have drawn upon here, allow for a more satisfactory presentation of information (that has always been available) on the distribution of low-income in a population.

Social transfers to low-income families grew, and grew substantially, during the 1980s but left scarcely a trace on the low-income rate among Canadian children, creating an impression that not much had changed over the decade (see for example, Picot and Myles, 1996). In fact, against a background of falling earnings, real incomes in low-income families were somewhat higher at the end of the decade than at the beginning. Transfers to low-income families continued rising through 1993, offsetting a significant share of the impact of the recession of the early 1990s. There is considerable interest in the capacity of the statistical system to monitor the impact of such changes. The Sens-Shorrocks-Thon low-income intensity index, and its adaption by Osberg and $\mathrm{Xu}$, will greatly facilitate this task. 


\section{Appendix A: Significant Differences in the SST Index and its Components}

Osberg and Xu (1998) use an intensive bootstrap method to calculate a standard approximation (the average value of two standard deviations of bootstrap estimates) to a $95 \%$ confidence interval for the SST index and its components based on the LICO and LIM-IAT for Canada and the province for all families. We have not replicated this effort but results reported in Table A-1 for Canada, Ontario (a large province), and Newfoundland (a small province) give an indication of the magnitude of change required for statistical significance and the sensitivity to sample size. As a rule of thumb, it is clear that in larger samples (e.g. all children) a change of .01 in the index or its components would be a conservative standard for statistical significance. In smaller samples (e.g. children in lone parent families) a change of .02 (for the rate) and .03 (for the gap) would be appropriate.

Table A-1: Statistically Significant Differences-Average Value of Two Standard Deviations of Bootstrap Estimates

\begin{tabular}{|l|c|r|r|r|r|r|}
\hline & \multicolumn{2}{|c|}{ SST Index } & \multicolumn{2}{c|}{ Rate } & \multicolumn{2}{c|}{ Gap } \\
\cline { 2 - 7 } & LICO & \multicolumn{1}{l|}{ LIM-IAT } & \multicolumn{1}{c|}{ LICO } & LIM-IAT & \multicolumn{1}{c|}{ LICO } & LIM-IAT \\
\hline & & & & & & \\
Canada & 0.0028 & 0.0029 & 0.0037 & 0.0044 & 0.0089 & 0.0092 \\
Ontario & 0.0047 & 0.0049 & 0.0054 & 0.0065 & 0.0204 & 0.0226 \\
Nfld. & 0.0085 & 0.0145 & 0.0109 & 0.0192 & 0.0279 & 0.0255 \\
\hline
\end{tabular}




\section{Appendix B: Results Based on the Relative LIM-IAT}

Table B-1: Change in LIM-IAT Based Low-Income Intensity and its Components, Pre and Post Tax/Transfers, Children Aged 0-17, 1981-89

\begin{tabular}{|l|c|r|r||c|c|r|}
\hline \multirow{2}{*}{} & \multicolumn{3}{|c|}{ Pre-Tax/Transfer LIM- IAT } & \multicolumn{3}{|c|}{ Post-Tax/Transfer LIM- IAT } \\
\cline { 2 - 3 } & $\mathbf{1 9 8 1}$ & $\mathbf{1 9 8 9}$ & \% Change & $\mathbf{1 9 8 1}$ & $\mathbf{1 9 8 9}$ & \% Change \\
\hline \multirow{3}{*}{ Low-Income Intensity } & & & & & & \\
Rate & 0.168 & 0.189 & $12.5 \%$ & 0.075 & 0.064 & $-14.7 \%$ \\
Gap & 0.156 & 0.167 & $7.1 \%$ & 0.114 & 0.111 & $-2.6 \%$ \\
Inequality in the Gap & 0.566 & 0.599 & $5.8 \%$ & 0.341 & 0.299 & $-12.3 \%$ \\
\hline
\end{tabular}

Table B-2: Changes in the First-Order Effects of Transfers/Taxes on Low-Income Intensity Among Canadian Children, LIM-IAT Based Measures, 1981 to 1989

\begin{tabular}{|l|c|c|c|}
\hline \multirow{2}{*}{} & \multicolumn{3}{|c|}{ Pre-Tax/Transfer LIM- IAT } \\
\cline { 2 - 4 } & Before Transfer/Taxes & After Transfer/Taxes & Difference \\
\hline & & & $-27.2 \%$ \\
Low-Income Intensity & $12.5 \%$ & $-14.7 \%$ & $-9.7 \%$ \\
Gap & $7.1 \%$ & $-2.6 \%$ & $-18.1 \%$ \\
Inequality in the Gap & $5.8 \%$ & $-12.3 \%$ & $0.6 \%$ \\
\hline
\end{tabular}

Table B-3: Change in LIM-IAT Based Low-Income Intensity and its Components, Pre and Post Tax/Transfers, Children Aged 0-17, 1986-96

\begin{tabular}{|l|c|c|c|c|c|c|}
\hline \multirow{2}{*}{} & \multicolumn{3}{|c|}{ Pre-Tax/Transfer } & \multicolumn{3}{c|}{ Post-Tax/Transfer } \\
\cline { 2 - 4 } \cline { 6 - 7 } & $\mathbf{1 9 8 6}$ & $\mathbf{1 9 9 6}$ & \% Change & $\mathbf{1 9 8 6}$ & $\mathbf{1 9 9 6}$ & \% Change \\
\hline & & & & & & \\
Low-Income Intensity & 0.201 & 0.257 & $27.9 \%$ & 0.070 & 0.076 & $8.6 \%$ \\
Rate & 0.181 & 0.213 & $17.7 \%$ & 0.115 & 0.133 & $15.7 \%$ \\
Gap & 0.591 & 0.653 & $10.5 \%$ & 0.312 & 0.298 & $-4.5 \%$ \\
Inequality in the Gap & 1.879 & 1.849 & $-1.6 \%$ & 1.930 & 1.921 & $-0.5 \%$ \\
\hline
\end{tabular}

Table B-4: Changes in the First-Order Effects of Transfers/Taxes on Low-Income Intensity Among Canadian Children, LIM-IAT Based Measures, 1986 to 1996

\begin{tabular}{|l|c|c|c|}
\hline \multirow{2}{*}{} & \multicolumn{3}{|c|}{ \% Change in Low-Income Intensity LIM-IAT } \\
\cline { 2 - 4 } & Before Transfer/Taxes & After Transfer/Taxes & Difference \\
\hline & & & \\
Low-Income Intensity & $27.9 \%$ & $8.6 \%$ & $-19.3 \%$ \\
Rate & $17.7 \%$ & $15.7 \%$ & $-2.0 \%$ \\
Gap & $10.5 \%$ & $-4.5 \%$ & $-15.0 \%$ \\
Inequality in the Gap & $-1.6 \%$ & $-0.5 \%$ & $1.1 \%$ \\
\hline
\end{tabular}


Table B-5: Changes in LIM-IAT Based Low-Income Intensity and Its Components, Pre and Post Transfers/Taxes, Children Aged 0-17, 1989-93, $1993-96$

\begin{tabular}{|l|c|c|c|c|c|}
\hline \multirow{2}{*}{} & \multicolumn{5}{|c|}{ Pre and Tax/Transfer } \\
\cline { 2 - 6 } & $\mathbf{1 9 8 9}$ & $\mathbf{1 9 9 3}$ & $\mathbf{1 9 9 6}$ & Change 89-93 & Change 93-96 \\
\hline \multirow{2}{*}{ Low-Income Intensity } & & & & & \\
Rate & 0.189 & 0.272 & 0.257 & $43.9 \%$ & $-5.5 \%$ \\
Gap & 0.167 & 0.226 & 0.213 & $35.3 \%$ & $-5.8 \%$ \\
Inequality of Gap & 0.599 & 0.655 & 0.653 & $9.3 \%$ & $-0.3 \%$ \\
\hline & 1.886 & 1.840 & 1.849 & $-2.4 \%$ & $0.5 \%$ \\
\hline & \multicolumn{7}{|c|}{ Post Tax/Transfer } \\
\cline { 2 - 7 } & $\mathbf{1 9 8 9}$ & $\mathbf{1 9 9 3}$ & $\mathbf{1 9 9 6}$ & Change 89-93 & Change 93-96 \\
\hline \multirow{2}{*}{ Low-Income Intensity } & 0.075 & 0.065 & 0.076 & $-13.3 \%$ & $16.9 \%$ \\
Rate & 0.114 & 0.119 & 0.133 & $4.4 \%$ & $11.8 \%$ \\
Gap & 0.341 & 0.282 & 0.298 & $-17.3 \%$ & $5.7 \%$ \\
Inequality of Gap & 1.932 & 1.929 & 1.921 & $-0.2 \%$ & $-0.4 \%$ \\
\hline
\end{tabular}

Table B-6: Changes in First-Order Effects of Transfer/Taxes on Low-Income Intensity, Children 0-17, 1989-93, 1993-96 LIM-IAT Based

\begin{tabular}{|l|c|c|c||c|c|c|}
\hline \multirow{2}{*}{} & \multicolumn{5}{|c|}{ Log Change in Low-Income Intensity LIM-IAT } \\
\cline { 2 - 4 } & \multicolumn{3}{|c|}{$\mathbf{1 9 8 9 - 9 3}$} & \multicolumn{3}{c|}{$\mathbf{1 9 9 3 - 9 6}$} \\
\cline { 2 - 4 } & $\begin{array}{c}\text { Before Taxes/ } \\
\text { Transfer }\end{array}$ & $\begin{array}{c}\text { After Taxes/ } \\
\text { Transfer }\end{array}$ & Difference & $\begin{array}{c}\text { Before Taxes/ } \\
\text { Transfer }\end{array}$ & $\begin{array}{c}\text { After Taxes/ } \\
\text { Transfer }\end{array}$ & Difference \\
\hline Low-Income Intensity & 0.364 & -0.143 & -0.507 & -0.057 & 0.156 & 0.213 \\
Rate & 0.303 & 0.043 & -0.260 & -0.059 & 0.111 & 0.170 \\
Gap & 0.089 & -0.190 & -0.279 & -0.003 & 0.055 & 0.058 \\
Inequality in the Gap & -0.025 & -0.002 & 0.023 & 0.005 & -0.004 & -0.009 \\
\hline
\end{tabular}




\section{Appendix C: Calculating "First-Order" Transfer Effects}

The standard method of estimating the "impact" of transfers (and taxes) on the low-income rate (e.g. McFate, Smeeding and Rainwater, 1995) is given by a estimating the rate before and after transfers/taxes and calculating the percentage (or proportional) reduction in the rate that "results" from transfers as in:

(1) $\quad \mathrm{TE}_{\text {rate }}=\left(\right.$ Rate $_{\text {after }}-$ Rate $\left._{\text {before }}\right) /$ Rate before

and equivalently for the SST index by:

(2) $\quad \mathrm{TE}_{\text {sst }}=\left(\mathrm{SST}_{\text {after }}-\mathrm{SST}_{\text {before }}\right) / \mathrm{SST}_{\text {before }}$

A change (or difference) in first-order effects $(\Delta \mathrm{TE})$ is given by the difference between the values of TE between $t_{2}$ and $t_{1}$. However, percentage changes in low-income intensity before and after transfers (and taxes) are usually quite large so that the percentage change approximation for this formulation rarely approximates its logarithmic equivalent, namely:

(3) $\quad \Delta \mathrm{TE}_{\mathrm{sst}}=\left(\ln \mathrm{SST}_{\text {after }}-\ln \mathrm{SST}_{\text {before }}\right)_{\mathrm{t} 2}-\left(\ln \mathrm{SST}_{\text {after }}-\ln \mathrm{SST}_{\text {before }}\right)_{\mathrm{t} 1}$

and a percentage change decomposition of change in SST does not work as a result.

However, rearranging terms in (3) gives:

(4) $\quad \Delta \mathrm{TE}_{\mathrm{sst}}=\left(\ln \mathrm{SST}_{\text {after-t2 }}-\ln \mathrm{SST}_{\text {after-t1 }}\right)-\left(\ln \mathrm{SST}_{\text {before-t2 }}-\ln \mathrm{SST}_{\text {before-t1 }}\right)$

And the percentage change approximation of (4) is simply:

(5) $\Delta \mathrm{TE}_{\mathrm{sst}}=\%$ Change After Transfers - \% Change Before Transfers

The magnitude of differences in this formulation are often small enough so that the percentage change decomposition of the SST index provides a reasonable approximation. In order that an increase/decrease in low-income intensity will have a positive/negative sign however, the sign in 5 is reversed (by subtracting the change after transfers from the change before transfers). 


\section{References}

Adams, I., W. Cameron, B. Hill and P. Penz. 1971. The Real Poverty Report. Edmonton: Hurtig.

Beach, C. M., G. A. Slotsve, and C.D. Howe Institute. 1996. Are We Becoming Two Societies? Income Polarization and the Myth of the Declining Middle Class in Canada. Toronto: C.D. Howe Institute.

Blank, R. and M. Hanratty. 1993. "Responding to need: a comparison of social safety nets in Canada and the United States." pp. 191-231 in Small Differences that Matter: Labor Markets and Income Maintenance in Canada and the United States, edited by David Card and Richard Freeman. Chicago: University of Chicago Press.

Federal/Provincial/Territorial Working Group on Social Development Research and Information. 1998. "Construction of a preliminary market basket measure of poverty." Ottawa: Human Resources Development Canada.

Foster, J.E. 1984. "On economic poverty: a survey of aggregate measures." Advances in Econometrics 3:215-251.

Foster, J.E., J. Greer and E. Thorbecke. 1984. "A class of decomposable poverty indices." Econometrica 52:761-766.

Foster, J.E. and A.F. Shorrocks. 1988. “Poverty orderings.” Econometrica 56:173-178.

Foster, J.E. and A.F. Shorrocks. 1991. "Subgroup consistent poverty indices." Econometrica 59:687-709.

Human Resources Development Canada. 1998. "The market basket measure: Constructing a new measure of poverty." Applied Research Bulletin 4 No. 2:1-4.

McFate, K. T. Smeeding and L. Rainwater. 1995. "Markets and states: poverty trends and transfer system effectiveness in the 1980s." pp. 29-66 in Poverty, Inequality and the Future of Social Policy, edited by K. McFate, R. Lawson, and W.J. Wilson. New York: Russell Sage.

Morissette, R., J. Myles and G. Picot. 1994. "What is Happening to Earnings Inequality in Canada?" Research Paper series No. 60. Analytical Studies Branch, Ottawa, Statistics Canada.

Osberg, L. and K. Xu. 1997. "International comparisons of poverty intensity: Index decomposition and bootstrap inferences." Working Paper No. 165, Luxembourg Income Study. 
Osberg, L. and K. Xu. 1998. "Poverty intensity: How well does Canada compare." Department of Economics, Dalhousie University.

Picot, G. and J. Myles. 1996. "Social transfers, changing family structure and low-income among children." Canadian Public Policy XXII:244-267.

Picot, G., J. Myles and W. Pyper. 1998. "Markets, families and social transfers: trends in lowincome among the young and the old, 1973-95." in Labour Markets, Social Institutions, and the Future of Canada's Children, edited by Miles Corak. Ottawa: Statistics Canada.

Podoluk, J.R. 1968. Incomes of Canadians. Ottawa: Dominion Bureau of Statistics.

Sen, A. 1976. "Poverty: an ordinal approach to measurement." Econometrica 44:219-231.

Senate of Canada. 1971. Poverty in Canada. Ottawa: Special Senate Committee on Poverty.

Shorrocks, A.F. 1995. "Revisiting the Sen poverty index.” Econometrica 63:1225-1230.

Thon, D. 1979. “On measuring poverty.” Review of Income and Wealth, 25: 429-440

Thon, D. 1983. “A poverty measure.” The Indian Economic Journal, 30:55-70

Wolfson, M.C., and J.M. Evans. 1989. "Statistics Canada's Low-Income Cut-Offs: methodological concerns and possibilities." Analytical Studies Branch, Ottawa, Statistics Canada.

Wolfson, M.C., and B. Murphy. 1998. "New Views on Inequality Trends in Canada and the United States" Monthly Labor Review, April.

$\mathrm{Xu}$, K. Forthcoming. "Statistical inference for the Sen-Shorrocks-Thon index of poverty intensity." Journal of Income Distribution. 